\title{
Cardiovascular abnormalities in end stage renal failure: the effect of anaemia or uraemia?
}

Department of Paediatric Nephrology, Royal Victoria Infirmary, Newcastle upon Tyne K P Morris M G Coulthard

\section{Department of} Paediatric Cardiology, Freeman Hospital, Newcastle upon Tyne

J R Skinner

$S$ Hunter

Correspondence to: Dr M G Coulthard Paediatric Nephrology, Royal Victoria Infirmary, Newcastle upon Tyne NE1 4LP.

Accepted 18 May 1994

\author{
K P Morris, J R Skinner, S Hunter, M G Coulthard
}

\begin{abstract}
Children with end stage renal failure and anaemia have an increased cardiac index and often gross ventricular hypertrophy. Correction of anaemia with recombinant human erythropoietin (r-HuEpo) for less than six months results in a reduction in the cardiac index without a significant reduction in left ventricular hypertrophy. Seven children receiving dialysis (group 1) were studied to determine whether a reduction in left ventricular hypertrophy would occur after a 12 month period of r-HuEpo. A decrease in the cardiac index was seen by six months, and a significant reduction in left ventricular mass index and cardiothoracic ratio was seen by 12 months.
\end{abstract}

Successful renal transplantation also results in a reduction in the cardiac index and left ventricular hypertrophy, but the relative contributions of correction of anaemia and correction of biochemical disturbance is unknown because they usually improve simultaneously. To investigate this, six children (group 2) who already had a mean haemoglobin concentration of $107 \mathrm{~g} / \mathrm{l}$ while receiving dialysis were followed up for 12 months after successful transplantation. They showed no significant change in haemoglobin concentration, but a dramatic improvement in biochemistry. There was no significant change in cardiovascular function. Anaemia is the more dominant influence on cardiovascular function in end stage renal failure.

(Arch Dis Child 1994; 71: 119-122)

Recombinant human erythropoietin ( $r-H u E p o)$ is now available to correct the anaemia of end stage renal failure. Studies in adult patients have shown that short term correction of anaemia (less than six months) results in a decrease in cardiac output without a significant reduction in left ventricular hypertrophy. ${ }^{12}$ We have shown that this is also true in children. ${ }^{3}$ Longer term studies in adult patients have shown that with continuing r-HuEpo treatment a reduction in left ventricular hypertrophy is seen. ${ }^{4-6}$

Successful renal transplantation results not only in the correction of anaemia, but also correction of the biochemical abnormalities caused by chronic renal dysfunction. Previous studies have shown that successful transplantation results in a decrease in cardiac output and a reduction in left ventricular hypertrophy in adults and children. ${ }^{7-9}$ These studies were performed before r-HuEpo became available, so most patients had been anaemic at the time of transplantation. It is therefore not clear from existing studies to what extent the changes in cardiovascular function are attributable to the correction of anaemia or to the correction of biochemical abnormalities.

The aims of this study were firstly to document the cardiovascular effects of 12 months of $\mathrm{r}-\mathrm{HuEpo}$ treatment in a group of children with end stage renal failure, and secondly to address whether anaemia or biochemical disturbance has a greater influence on cardiovascular function. This was achieved by studying a second group of children who were not anaemic at the time of transplantation, in most as a result of ongoing $r-H u E p o$ treatment.

\section{Methods}

Two groups of children were studied. Table 1 summarises the range of underlying disorders and other clinical details at the start of the

Table 1 Clinical details of the 13 children at the time of entering the study

\begin{tabular}{|c|c|c|c|c|c|c|c|}
\hline $\begin{array}{l}\text { Patient } \\
\text { No }\end{array}$ & $\operatorname{Sex}$ & $\begin{array}{l}\text { Age } \\
\text { (years) }\end{array}$ & $\begin{array}{l}\text { Haemoglobin } \\
(\mathrm{g} / \mathrm{l})\end{array}$ & $\begin{array}{l}\text { Plasma } \\
\text { creatinine } \\
(\mu \text { moll })\end{array}$ & $\begin{array}{l}\text { Mode of } \\
\text { dialysis }\end{array}$ & Diagnosis & $\begin{array}{l}\text { Treatment for } \\
\text { hypertension }\end{array}$ \\
\hline $\begin{array}{c}\text { Group } 1 \\
1 \\
2 \\
3 \\
4 \\
5 \\
6 \\
7\end{array}$ & $\begin{array}{l}\mathbf{M} \\
\mathbf{F} \\
\mathbf{M} \\
\mathbf{M} \\
\mathbf{M} \\
\mathbf{M} \\
\mathbf{M}\end{array}$ & $\begin{array}{r}9 \cdot 2 \\
5 \cdot 4 \\
7 \cdot 2 \\
14 \cdot 5 \\
8 \cdot 3 \\
11 \cdot 1 \\
3 \cdot 2\end{array}$ & $\begin{array}{l}90 \\
72 \\
68 \\
71 \\
85 \\
47 \\
68\end{array}$ & $\begin{array}{r}691 \\
403 \\
530 \\
1053 \\
718 \\
841 \\
516\end{array}$ & $\begin{array}{l}\text { PROD } \\
\text { PROD } \\
\text { PROD } \\
\text { PROD } \\
\text { PROD } \\
\text { PROD } \\
\text { PROD }\end{array}$ & $\begin{array}{l}\text { PUV } \\
\text { Dysplasia } \\
\text { Dysplasia } \\
\text { FSGS } \\
\text { PUV } \\
\text { Familial HUS } \\
\text { Dysplasia }\end{array}$ & $\begin{array}{l}\text { No } \\
\text { No } \\
\text { No } \\
\text { Yes } \\
\text { Yes } \\
\text { Yes } \\
\text { No }\end{array}$ \\
\hline $\begin{array}{c}\text { Group } 2 \\
8 \\
9 \\
10 \\
11 \\
12 \\
13\end{array}$ & $\begin{array}{l}\mathbf{M} \\
\mathbf{M} \\
\mathbf{F} \\
\mathbf{F} \\
\mathbf{M} \\
\mathbf{F}\end{array}$ & $\begin{array}{c}7 \cdot 2 \\
13 \\
9 \cdot 6 \\
12 \cdot 1 \\
4 \cdot 3 \\
10\end{array}$ & $\begin{array}{r}103 \\
101 \\
97 \\
109 \\
117 \\
112\end{array}$ & $\begin{array}{l}368 \\
722 \\
946 \\
567 \\
562 \\
322\end{array}$ & $\begin{array}{l}\text { Haemodialysis } \\
\text { PROD } \\
\text { PROD } \\
\text { PROD } \\
\text { PROD } \\
\text { Predialysis }\end{array}$ & $\begin{array}{l}\text { PUV } \\
\text { FSGS } \\
\text { Unknown } \\
\text { Cystinosis } \\
\text { Congenital NS } \\
\text { FSGS }\end{array}$ & $\begin{array}{l}\text { No } \\
\text { Yes } \\
\text { Yes } \\
\text { No } \\
\text { Yes } \\
\text { Yes }\end{array}$ \\
\hline
\end{tabular}

PROD=peritoneal rapid overnight dialysis; HUS = haemolytic uraemic syndrome; NS=nephrotic syndrome; PUV=posterior urethral valves; FSGS=focal segmental glomerulosclerosis. 
Table 2 Parameters measured on electrocardiography and echocardiography

\begin{tabular}{cc}
\hline Electrocardiography & P wave (II), Q wave (III, V5), R wave \\
& (aVR, V2, V5), S wave (V2, V5), T \\
& wave (V2, V5), PR interval (II), QRS \\
axis, QRS interval (V5), QTc interval & \\
& (V5), R/S ratio (V1, V5), RV5+SV2 \\
Echocardiography & \\
Cross sectional & Aortic root diameter \\
M mode & Left atrial diameter, interventricular sep- \\
& tum, left ventricular posterior wall, left \\
& ventricular end diastolic diameter, left \\
ventricular end systolic diameter & CW: aortic stroke distance \\
Doppler & PW: peak diastolic flow (E and A waves) \\
& mitral and tricuspid flow
\end{tabular}

$\mathrm{PW}=$ pulsed wave; $\mathrm{CW}=$ continuous wave .

study. Group 1 consisted of seven children with end stage renal failure and anaemia who were studied before starting r-HuEpo treatment and then after six and 12 months of treatment. Group 2 consisted of six children with end stage renal failure who were studied before renal transplantation and again after six and 12 months of graft function. The initial haemoglobin concentration of group 1 children was significantly lower than group 2 children ( $p=0.0002)$, with the highest value in group 1 less than the lowest value in group 2 (table 1). Four children in group 2 were already receiving r-HuEpo and the remaining two maintained a higher haemoglobin concentration without the need for $\mathrm{r}$-HuEpo. There was no significant difference between the groups in age range, baseline renal function, or the number of children receiving antihypertensive treatment (table 1).

Group 1 received subcutaneous r-HuEpo twice a week at a starting dose of 50 units/kg/week. Thereafter the dose was adjusted to maintain a target haemoglobin concentration of $105-120 \mathrm{~g} / \mathrm{l}$. All children were assessed by chest radiography, electrocardiography, and echocardiography. Systolic and diastolic blood pressure were measured by auscultation using the largest cuff that could be applied to the upper arm. The cardiothoracic ratio was measured by a blinded observer on chest radiographs performed in the erect position at full inspiration, at baseline, and 12 months into the study. A standard 12 lead electrocardiogram was obtained in a semirecumbent position after five minutes' rest (Marquette Instruments).

A single experienced observer (JRS) performed all the echocardiograms using the same Hewlett Packard Sonos 1000 machine. The observer had no knowledge of whether the patients had been in renal failure and receiving r-HuEpo, or had been transplanted. Details of the echocardiography methodology have been described in detail previously. ${ }^{3}$ Table 2 gives a list of the electrocardiographic and echocardiographic measurements. From these it was possible to derive left ventricular stroke volume, cardiac output, and left ventricular mass. ${ }^{3}$ Division of these variables by the body surface area of the child creates an 'index' value which then allows comparisons between individuals of different size. Diastolic function was assessed by the measuring peak inflow velocity in the rapid early (E) filling phase of diastole and the later atrially mediated phase (A). Normally the early phase has a higher velocity than the atrially mediated phase, such that the normal E:A ratio is greater than 1.0 .

\section{Results}

Table 3 summarises the relevant results.

\section{GROUP 1}

Treatment with $\mathrm{r}-\mathrm{HuEpo}$ resulted in a significant increase in the mean haemoglobin concentration from 72 to $118 \mathrm{~g} / \mathrm{l}$ after six months of treatment $(p=0.0003)$ (figure) which was maintained thereafter. In association with this there was a reduction in left ventricular end diastolic diameter and a significant decrease in the cardiac index $(p=0.002)$, predominantly due to a reduction in left ventricular stroke index. No significant change in left ventricular posterior wall or interventricular septal thickness was seen during the study, but a significant reduction in left ventricular mass index was seen after 12 months of $r$-HuEpo treatment $(p=0.02)$, indicating a reduction in left ventricular hypertrophy. After 12 months of treatment the mean cardiothoracic ratio had also decreased from $50 \cdot 1$ to $45.9 \% \quad(p=0 \cdot 005)$. No significant

Table 3 Echocardiographic, radiographic, and blood pressure changes in the two groups; values are mean (SD)

\begin{tabular}{|c|c|c|c|c|c|c|}
\hline & \multicolumn{3}{|c|}{ Group 1: $r-H u-E p o$} & \multicolumn{3}{|c|}{ Group 2: renal transplantation } \\
\hline & Baseline & $\begin{array}{l}\text { After } \\
\text { six months } \\
\text { of } r-H u E p o\end{array}$ & $\begin{array}{l}\text { After } \\
12 \text { months } \\
\text { of } r \text {-HuEpo }\end{array}$ & Baseline & $\begin{array}{l}\text { Six months } \\
\text { after } \\
\text { transplantation }\end{array}$ & $\begin{array}{l}\text { Twelve months } \\
\text { after } \\
\text { transplantation }\end{array}$ \\
\hline $\begin{array}{l}\text { Haemoglobin }(\mathrm{g} / \mathrm{l}) \\
\text { Plasma creatinine }(\mu \mathrm{mol} / \mathrm{l}) \\
\text { Cardiac index }\left(1 / \mathrm{min} / \mathrm{m}^{2}\right) \\
\text { Heart rate }(\mathrm{beats} / \mathrm{min}) \\
\text { Stroke index }\left(\mathrm{ml} / \mathrm{m}^{2}\right) \\
\text { LVEDD }(\mathrm{cm}) \\
\text { LVESD }(\mathrm{cm}) \\
\text { IVS }(\mathrm{cm}) \\
\text { LVPW }(\mathrm{cm}) \\
\text { LV mass index }\left(\mathrm{g} / \mathrm{m}^{2}\right) \\
\text { Mean blood pressure }(\mathrm{mm} \mathrm{Hg}) \\
\text { PVR (mm Hg/min } / \mathrm{l}) \\
\text { Shortening fraction }(\%) \\
\text { Cardiothoracic ratio }(\%) \\
\text { Mitral valve E:A ratio }\end{array}$ & $\begin{array}{l}72(14) \\
679(221) \\
7 \cdot 65(1 \cdot 8) \\
99 \cdot 7(15 \cdot 2) \\
77 \cdot 6(19 \cdot 6) \\
3 \cdot 50(0 \cdot 6) \\
2 \cdot 23(0 \cdot 6) \\
0 \cdot 88(0 \cdot 2) \\
0 \cdot 76(0 \cdot 1) \\
94 \cdot 1(20 \cdot 3) \\
77 \cdot 7(26 \cdot 4) \\
14 \cdot 0(5 \cdot 8) \\
36 \cdot 9(6 \cdot 8) \\
50 \cdot 1(4 \cdot 7) \\
1 \cdot 20(0 \cdot 8)\end{array}$ & $\begin{array}{l}118(17)^{\star \star \star} \\
725(193) \\
5 \cdot 23(2 \cdot 0)^{\star \star} \\
89 \cdot 9(14 \cdot 0) \\
57.8(20 \cdot 6)^{\star \star} \\
3 \cdot 18(0 \cdot 5)^{\star \star} \\
2 \cdot 03(0 \cdot 5) \\
0 \cdot 86(0 \cdot 3) \\
0 \cdot 68(0 \cdot 2) \\
73 \cdot 1(21 \cdot 0) \\
73 \cdot 7(17 \cdot 6) \\
22 \cdot 7(6 \cdot 8)^{\star} \\
36 \cdot 3(7 \cdot 5) \\
\overline{1.41(0 \cdot 4)}\end{array}$ & $\begin{array}{l}117(18)^{\star \star} \\
720(167) \\
5 \cdot 81(1 \cdot 4)^{\star \star} \\
93 \cdot 3(19 \cdot 2) \\
63 \cdot 5(14 \cdot 6)^{\star \star} \\
3 \cdot 42(0 \cdot 7) \\
2 \cdot 16(0 \cdot 4) \\
0 \cdot 81(0 \cdot 2) \\
0 \cdot 72(0 \cdot 2) \\
80 \cdot 8(18 \cdot 7)^{\star} \\
70 \cdot 7(11 \cdot 1) \\
16 \cdot 1(5 \cdot 6) \\
36 \cdot 4(3 \cdot 7) \\
45 \cdot 9(4 \cdot 4) \\
2 \cdot 08(1 \cdot 0)\end{array}$ & $\begin{array}{l}107(8) \\
581(231) \\
6 \cdot 22(2 \cdot 0) \\
91 \cdot 2(11 \cdot 0) \\
67.6(19 \cdot 6) \\
3.95(0 \cdot 3) \\
2.58(0 \cdot 2) \\
0 \cdot 85(0 \cdot 3) \\
0 \cdot 72(0 \cdot 2) \\
95 \cdot 7(19 \cdot 5) \\
82 \cdot 7(12 \cdot 8) \\
16.5(2 \cdot 3) \\
34.5(7 \cdot 2) \\
50.0(1 \cdot 8) \\
1.45(0 \cdot 1)\end{array}$ & $\begin{array}{l}112(11) \\
79(21)^{\star \star} \\
5 \cdot 55(0 \cdot 8) \\
99 \cdot 8(17 \cdot 1) \\
56.4(9 \cdot 8) \\
3.89(0 \cdot 3) \\
2.48(0 \cdot 1) \\
0.81(0 \cdot 1) \\
0.67(0 \cdot 1) \\
85 \cdot 3(15 \cdot 6) \\
75 \cdot 2(10 \cdot 1) \\
14 \cdot 4(1 \cdot 7) \\
36 \cdot 3(5 \cdot 0) \\
\overline{1} \cdot 61(0 \cdot 3)\end{array}$ & $\begin{array}{l}115(14) \\
77(16)^{\star \star} \\
5 \cdot 42(1 \cdot 1) \\
89 \cdot 5(1 \cdot 3) \\
60 \cdot 7(9 \cdot 5) \\
4 \cdot 03(0 \cdot 2) \\
2 \cdot 53(0 \cdot 2) \\
0 \cdot 86(0 \cdot 3) \\
0 \cdot 80(0 \cdot 2) \\
86 \cdot 7(22 \cdot 1) \\
77 \cdot 7(19 \cdot 0) \\
13.4(2 \cdot 6) \\
37 \cdot 2(4 \cdot 3) \\
51.3(0 \cdot 8) \\
1.80(0 \cdot 2)\end{array}$ \\
\hline
\end{tabular}

${ }^{\star} \mathrm{p}<0.05,{ }^{\star \star} \mathrm{p}<0.01,{ }^{\star \star \star} \mathrm{p}<0.001$; comparing values within each group (paired $t$ test). PVR=peripheral vascular resistance, calculated from mean arterial blood pressure/cardiac output; $L V E D D=$ left ventricular end diastolic diameter; $L V E S D=l$ left ventricular end systolic diameter; IVS=interventricular septum; LVPW =left ventricular peak diastolic flow. 

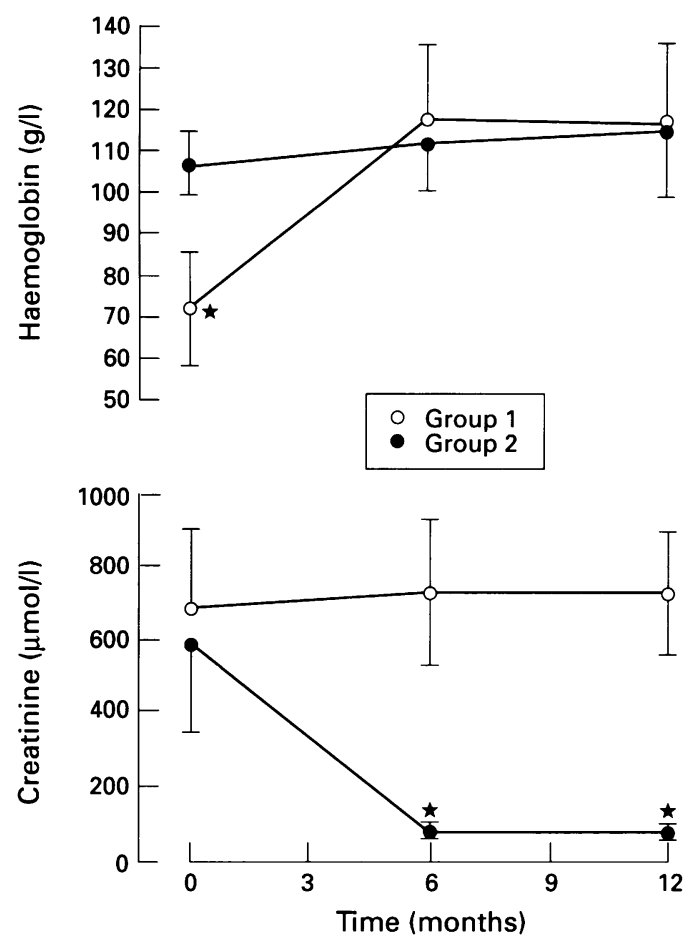

Changes in haemoglobin and creatinine concentration over the 12 month period in group 1 ( $r-H u E p o)$ and group 2 (transplantation). Mean (SD) values are shown; ${ }^{\star}$ indicates values significantly lower than other values $(p<0 \cdot 01)$.

change was seen on the electrocardiogram, plasma biochemistry (urea, creatinine, calcium phosphate, parathyroid hormone), or blood pressure. A trend towards an improvement in diastolic ventricular function was seen, as assessed by an increase in the mitral valve $\mathrm{E}: \mathrm{A}$ ratio.

\section{GROUP 2}

This group of children entered the study with a lower cardiac index, stroke index, and heart rate than those in group $1_{2}$ though the differences did not reach statistical significance. This probably reflected the higher initial haemoglobin concentration in this group (figure). As expected, a dramatic improvement in plasma biochemistry occurred, represented in the figure by the plasma creatinine concentration and contrasted with the stable plasma creatinine seen in group 1 children. During the year after transplantation no significant change was seen in haemoglobin concentration, cardiac index, left ventricular wall thickness or mass index, or cardiothoracic ratio (table 3 ). No change was seen in the electrocardiogram or blood pressure during the study. As in group 1 children, a trend towards an improvement in diastolic function was seen.

\section{Discussion}

Several studies have now assessed the cardiac effects of r-HuEpo in patients with end stage renal failure and anaemia. Most have shown a decrease in cardiac index even after short treatment periods as a result of a reduction in stroke index, ${ }^{24}$ heart rate, ${ }^{5}$ or both. ${ }^{3}{ }^{10}$ Most short term studies (less than six months) in adult patients have not shown a reduction in left ventricular mass, ${ }^{12}$ whereas longer term studies have. ${ }^{4-6}$ We have previously shown similar short term effects in children with end stage renal failure and anaemia, with a reduction in cardiac index without a significant reduction in left ventricular mass. ${ }^{3}$

The results of this study are in agreement with adult studies of similar duration, showing a reduction in left ventricular hypertrophy and cardiac size in addition to a reduction in cardiac index. These are important findings as left ventricular hypertrophy is known to be a powerful predictor of cardiovascular mortality in patients with ${ }^{11}$ or without renal disease. ${ }^{12}$ It is not yet known whether a reduction in left ventricular hypertrophy as a result of r-HuEpo treatment will in turn lead to a reduction in cardiovascular mortality.

Abnormalities of diastolic ventricular function have been reported in adults and children with end stage renal failure. ${ }^{1314}$ Typically, the peak $\mathrm{E}$ wave velocity is decreased and the A wave velocity increased so that the E:A ratio is also decreased. During this study we documented an increase in mitral valve E:A ratio with increasing time receiving $\mathrm{r}-\mathrm{HuEpo}$ treatment. This ratio is affected by many haemodynamic factors, including an alteration in heart rate. None the less, it is tempting to speculate that this increase in the ratio may reflect improving ventricular compliance as a result of a reduction in left ventricular hypertrophy, though one study in adult patients receiving peritoneal dialysis found no influence of left ventricular mass on left ventricular diastolic function. ${ }^{15}$

In this study we have attempted to identify whether correction of anaemia or correction of biochemical disturbance is the more important factor in improving cardiovascular function after renal transplantation. Hypertension plays an important part in determining the severity of cardiac abnormalities in end stage renal failure, ${ }^{14}$ and its control is known to contribute to the cardiac benefits seen after renal transplantation. ${ }^{9}$ Blood pressure was well controlled throughout the study, however, with no significant difference between the two groups. Significant improvements in cardiovascular function were seen in the r-HuEpo treated group, who showed a marked increase in haemoglobin concentration without any change in biochemical markers of 'uraemia'. By comparison, the group undergoing renal transplantation showed a marked improvement in biochemistry without a significant change in haemoglobin concentration. In this group no significant change was seen in any of the measured cardiovascular parameters, perhaps reflecting a higher haemoglobin concentration and milder cardiovascular abnormalities at the start of the study. These data suggest that anaemia has a greater influence on cardiovascular function than any biochemical abnormality, and is likely to be the key factor responsible for the cardiovascular changes reported after renal transplantation. 
1 Teruel JL, Pascual J, Jimenez M, et al. Hemodynamic changes in hemodialysis patients during treatment with recombinant human erythropoietin. Nephron 1991; 58: 135-7.

2 Tagawa $H$, Nagano $M$, Saito $H$, Umezu $M$, Yamakado $M$. Echocardiographic findings in hemodialysis patients treated with recombinant human erythropoietin: proposal for a hematocrit most beneficial to hemodynamics. Clin for a hematocrit most

3 Morris KP, Skinner JR, Hunter S, Coulthard MG. Short term correction of anaemia with recombinant human erythropoietin and reduction of cardiac output in end stage renal failure. Arch Dis Child 1993; 68: 644-8.

4 Pascual J, Teruel JL, Moya JL, Liano F, Jimenez-Mena M, Ortuno J. Regression of left ventricular hypertrophy after partial correction of anaemia with erythropoietin in patients on haemodialysis; a prospective study Clin Nephrol 1991; 35: 280-7.

5 Cannella G, La Canna G, Sandrini $M$, et al. Renormalization of high cardiac output and of left ventricular size following long-term recombinant human erythropoietin treatment of anaemic dialysed uremic patients. Clin Nephrol 1990; 6: 272-8.

6 Zehnder $C$, Zuber M, Sulzer M, et al. Influence of longterm amelioration of anemia and blood pressure control on left ventricular hypertrophy in hemodialyzed patients. Nephron 1993; 61: 21-5.

7 Lai KN, Barneden L, Mathew TH. Effect of renal transplantation on left ventricular function in hemodialysis patients. Clin Nephrol 1982; 18: 74.
8 O'Regan S, Douste-Blazy MY, Ducharme G, Fouron JC, Davignon A. Renal transplantation and cardiac function in pediatric patients. Clin Nephrol 1982; 17: 237-40.

9 Teruel JL. Regression of left ventricular hypertrophy after renal transplantation. A prospective study. Transplantation 1987; 43: 307-9.

10 London GM, Zins B, Pannier B, et al. Vascular changes in hemodialysis patients in response to recombinant human hemodialysis patients in response to recombina

erythropoietin. Kidney Int 1989; 36: 878-82.
11 Levy D, Garrison RJ, Savage DD, Kannel WB, Castelli WP. Prognostic implications of echocardiographically determined left ventricular mass in the Framingham heart study. N Engl $\mathcal{F}$ Med 1990; 322: 1561-6.

12 Parfrey PS, Harnett JD, Griffiths SM, et al. The clinical course of left ventricular hypertrophy in dialysis patients. Nephron 1990; 55: 114-20.

13 Huting J, Kramer W, Reitinger J, Kuhn K, Schutterle G, Wizemann $V$. Abnormal diastolic left ventricular filling by pulsed Doppler echocardiography in patients on conpulsed Doppler echocardiography in patients on con36: $21-8$.

14 Morris KP, Skinner JR, Wren C, Hunter S, Coulthard MG. Cardiac abnormalities in children with end stage renal failure and anaemia. Arch Dis Child 1993; 68: $637-43$.

15 Huting J, Alpert MA. Course of left ventricular diastolic dysfunction in end-stage renal disease on long-term continuous ambulatory peritoneal dialysis. Clin Nephrol 1993; 39: 81-7. 